\title{
INTRODUCTION: SPECIAL ISSUE ON SUSTAINABILITY IN THE EVENT MANAGEMENT SECTOR
}

Sustainability since the early 1990s has emerged as a societal "mega-trend" supported, at least rhetorically, by all major sectors of the economy. This holds true also for the event sector, although arguably progress in the latter has not been as advanced as what has been achieved in the hospitality sector. Fortunately, recent academic books have served to disseminate theoretical and empirical information on the concepts of sustainability within the event sector. Specifically, Raj and Musgrave (2009) provide a greater understanding of the economic, social, and environmental impacts of events, and provide a series of management models on the financial feasibility of sustainable events. Another book by Jones (2010) provides a more "hands-on" approach to managing sustainability from a festival organizers point of view.

This collation of six academic articles represents a substantial contribution to the broadening knowledge based about sustainability in the event industry sector, revealing a diverse array of themes and methodologies. The opening article by Ensor, Robertson, and Ali-Knight examines the perceptions and beliefs about sustainability of elite festival leaders, and attests to the relatively incipient state of its engagement. In-depth interviews employing a repertory grid method are employed. Their findings identified four key success factors associated with creating and directing a successful festival: the event focus, leadership strength, mixed funding (i.e., reliance on commercial arrangements rather than public sector funding only), and organization culture (i.e., strong institutional memory and legacy). Moreover, these same festival leaders overwhelmingly interpreted the concept of sustainability as being synonymous with a festival's survival (i.e., the longevity of the event itself) rather an environmental concern (i.e., particular theme, programming aspect, or management of an environmental impact associated with a particular event). Only 3\% of all constructs elicited from festival leaders related to the environment.

In a similar view, Reid and Ritchie argue that occupational health and safety requirements, legal duty of care, and the capacity of an organization to deal with risks and crisis are important considerations for the sustainability of the event organization and the event itself. Their qualitative study examined event managers' attitudes, beliefs, and perceived constraints to implementing risk management planning in Southeast Queensland, Australia. Findings varied considerably based on an event manager's prior experience, organizational size, and level of professionalism. They found event managers were overwhelmingly concerned with physical and safety risks at the expense of other risks (i.e., social and environmental). These findings are in direct contrast to the holistic risk management planning approach advocated by the Australian New Zealand International Standards.

The third article, by Gration, Arcodia, Raciti, and Stokes, identifies major elements of "festivalscapes" having implications for sustainable site management. The Australian Woodford Folk Festival and National Country Music Festival were chosen as case studies owing to their similar nonurban settings and close proximity to a major urban center. Unlike the previous two articles, event managers were familiar with the concept of sustainable event management and were conscious that their decision-making processes did have an impact on a festival attendee's perception of their environment 
or festivalscape. Focus groups with festival attendees were also conducted. Interviewees probed festival attendees to understand their relationship between the event and place (or site), their consumption patterns, and sense of connectedness to the festivalscape. Three major themes emerged, which reinforced the need for mangers to take into the blending of the festivalscape (i.e., natural, manmade, and social environment) to produce optimal experience for festival goers on site.

The next articles in this collation examine the concept of sustainability in two different contexts. Merrilees and Marles explore the adoption of environmental policies and practices by a major Australian business event, the Sanctuary Cove International Boat Show. In line with most business events, green aspects took a "back seat" to marketing and economic matters. Overall, The Boat Show was geared toward maximizing patron and exhibitor satisfaction. No evidence of greenwashing existed since this event did not purport to be or profile itself as green event according to their policies, marketing literature, or website. The authors make particular pains to note that no environmental policy or strategy existed at their time of study. However, Merrilees and Marles were able to discern that The Boat Show did engage in a number of green business practices that reduced the environmental impact of their event. The case study approach highlights a number of these green initiatives - key among them new planning and policy initiatives, reduced waste and energy consumption, and reduced environmental damage and negative community impact. The integration of environmental management into normal operations is also discussed.

Hvenegaard subsequently examines potential conservation benefits of wildlife festivals. As an ecotourism activity, wildlife festivals according to the author should also promote conservation goals, specifically: incentives to establish protected areas; generation of wildlife and habitat management revenue; positive economic impacts for nearby com- munities (including resident participation in conservation efforts); offering alternatives to other more damaging uses; and support for conservation by education for both the resident and nonresident participants. Each one of these conservation benefits is explored in more detail through the synthesis of the wider academic literature and usage of wildlife festival data where available. Strategies for managing the economic impacts of wildlife festivals to promote conservation are also discussed.

The last article, by Rodgers and Anastasiadou, conducts an extensive review of the social impacts of festivals, particularly from a community perspective. The authors propose an innovative Community Involvement Framework that can be used by festival organizers to widen local participation. Results from four community-based focus groups with festival organizers and members of the local community in Edinburgh revealed the need for wider engagement at the school level, in volunteering opportunities, participation in the decisionmaking process, accessibility, and business cooperation. A series of involvement methods and example of indicators are proposed for each of these five community engagement levels.

We hope that these contributions will provide you with valuable assistance in your own efforts to promote the sustainability of the events sector.

\section{References}

Jones, M. (2010). Sustainable event management: A practical guide. London, UK: Earthscan.

Raj, R., \& Musgrave, J. (2009). Event management sustainability. Wallingford, Oxfordshire, UK: CABI International.

Guest Editor

Dr. Laura Jane Lawton

Department of Tourism, Hotel, Leisure and Sport Management

Griffith Business School-Gold Coast Campus Griffith University

Queensland, Australia 